\title{
Profesor Doctor Roque Kraljevic Orlandini
}

ENRIQUE LAVAL R.

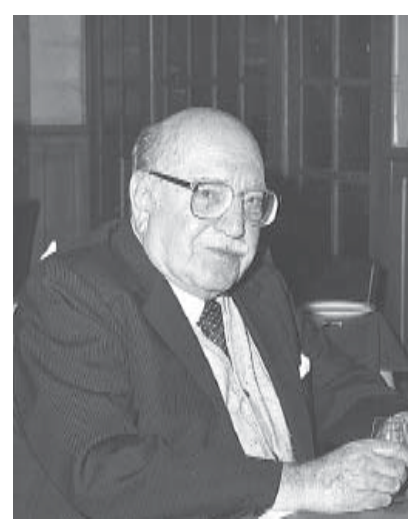

Presentamos a través de esta primera contribución de Enrique Laval R, Editor de Figuras de la Infectología Chilena, y las que se publicarán en números siguientes, el aporte que aquellos médicos distinguidos por la Sociedad Chilena de Infectología como Socios Honorarios, han hecho al desarrollo y posicionamiento de nuestra especialidad en el país.

El Editor

En el homenaje al profesor Roque Kraljevic, realizado en el Congreso Chileno de Infectología, en Valdivia en 1997, la doctora Enna Zunino Martini, actual Jefa de Servicio del Hospital de Enfermedades Infecciosas de Santiago y Profesora de la especialidad, en hermosas y sentidas palabras, realizó una muy acertada semblanza del doctor Roque Kraljevic, que con orgullo la suscribo plenamente: "en verdad, mencionarlo todo es imposible, mas allá de su labor gigantesca, quien ha concentrado en sí mismo, algo de padre, de modelo, de crítico de maestro y amigo, porque nos acogió cariñosamente como discípula, dándonos pautas y enseñanzas que nos han guiado en nuestros quehaceres profesionales, viéndolo siempre brillante en la investigación, en la clínica, la docencia y la administración, desarrollando su labor tanto en Chile, como en otros países, defendiendo rigurosamente conceptos básicos de la Infectología, corrigiendo lo que a su espíritu sagaz, nunca escapa. Finalmente, cuando el temido Profesor Kraljevic, nos permitió conocer su sensibilidad, se nos fue transformando en don Roque, más cercano, más nuestro".

Sí, es cierto, reseñar en pocas palabras su labor docente, asistencial y de investigación, así como destacar la proyección que ha señalado para nuestra especialidad de Enfermedades Infecciosas, sin duda que es difícil tarea, tal como lo expresé en el homenaje que le rindió la Sociedad Chilena de Neurología, Psiquiatría y Neurocirugía, en agosto de $1973^{2}$.
El Profesor Kraljevic nació en la ciudad de Iquique el 2 de enero de 1911, realizando sus estudios primarios y secundarios en Valparaíso, obteniendo su licencia secundaria en 1928. Al año siguiente ingresó a la Escuela de Medicina de la Universidad de Chile ${ }^{3}$.

¿Qué lo motivó a estudiar medicina?, fue la pregunta que se le formuló en una entrevista publicada en la Revista Chilena de Salud Pública del año 2002. "Cuando era niño tuve muchas enfermedades y siempre sentí admiración, simpatía y afecto por aquellos médicos que me atendieron a mí y a mi familia. La imagen del doctor Murúa que llegaba a su casa, "calmando la angustia de mi madre, inundando el hogar de paz y tranquilidad", continúa el Profesor Kraljevi, explayándose sobre "este médico de blanca barba de fines del siglo XIX y reloj que pendía del chaleco, con una cadena de plata, con el cual me tomaba parsimoniosamente el pulso", que me influyó en forma decisiva para "ser primero un médico de vocación y segundo para marcar mi actitud como médico frente a mis pacientes", explica el doctor Kraljevic ${ }^{4}$.

En 1937 obtuvo su título de médico-cirujano. Su tesis fue "La acción anti-estreptocóccica de la sulfacrisoidina en varias especies animales", la que fue aprobada con distinción máxima ${ }^{3}$.

Pocos años antes de que obtuviera su título de médico, fue ayudante de Bacteriología en la Cátedra del Profesor Hugo Vaccaro, pero en realidad empezó a vislumbrar la importancia del estudio 
de las enfermedades infecciosas en la Clínica Médica del Profesor Exequiel González Cortés. Ahí comprendió la trascendencia de la formación microbiológica para asumirla cabalmente al problema de la clínica de las enfermedades por agentes patógenos vivos, contribuyendo también a ese fin su inquietud por la epidemiología, colaborando en la Dirección General de Sanidad, como asesor clínico de la Jefatura Provincial de Santiago.

El año 1942 fue enviado a la República Argentina por la Honorable Junta de Beneficencia, permaneciendo desde abril a octubre de ese año en la Cátedra de Enfermedades Infecciosas del Profesor Carlos Fonso Gandolfo, en el Hospital Muñiz e Instituto Penna de Buenos Aires. También en aquella oportunidad fue alumno del curso de Inmunología aplicada a la Clínica, dictado por el Profesor Bachman y del Profesor D'Alessandro en el de Enfermedades Infecciosas comunes al hombre y a los animales.

Volvió enseguida a Chile, después de haber obtenido el título de especialista en Enfermedades Infecciosas y fue designado Jefe de Clínica del Profesor Abraham Horwitz, en el Servicio de Medicina y Enfermedades Infecciosas del Hospital Ramón Barros Luco, cuyo jefe era el Profesor Lucio Córdova Labarca.

En 1944, los Profesores Abraham Horwitz (Profesor Extraordinario de Enfermedades Infecciosas de la Universidad de Chile, 1942) y Roque Kraljevic, iniciaban la docencia de la Clínica de las Enfermedades Infecciosas, dentro del Programa del Curso Principal para Especialistas en Salud Pública de la Escuela de Salubridad de la Universidad de Chile, lo que constituyó un hito histórico en la enseñanza de la especialidad para estudiantes de post-grado en Chile, como una novedad en una Escuela de Salud Pública, tanto en el país como en el extranjero. Esta actividad docente se amplió, en 1946, cuando el doctor José Manuel Balmaceda Ossa, Profesor de Medicina de la Universidad Católica de Chile, invitó a los doctores Horwitz y Kraljevic para iniciar la docencia de las enfermedades infecciosas a sus alumnos del $5^{\circ}$ Año, como curso integrado de medicina interna y en calidad de Profesores Agre$\operatorname{gados}^{2,5}$.

Comenzó, entonces, el Profesor Kraljevic, a sentir que sus deseos tanto tiempo acariciados, de efectuar un Curso de Clínica de las Enfermedades Infecciosas, dentro del currículo, si bien autónomo, pero integrado al de Clínica Médica y a otras especialidades, habrían de cumplirse en plazos ya no tan lejanos ${ }^{2}$.

Desde largos años había sido considerada por las autoridades de la antigua Beneficencia, la necesidad de integrar los cuadros de la asistencia hospitalaria de Santiago con un establecimiento especializado para el aislamiento y tratamiento de enfermos infecto-contagiosos agudos.

A partir de fines de 1938, entró a formar parte de la Junta Central de Beneficencia el Profesor Lucio Córdova Labarca. Dicho organismo prestó su aprobación a la indicación que el Profesor Córdova presentó para proceder a la construcción en Santiago de un Pabellón, anexado al Hospital Ramón Barros Luco, para la atención de los enfermos infecciosos. Fueron designados tres médicos para organizar dicho Pabellón y que habían sobresalido en el Servicio de Medicina y Enfermedades Infecciosas de aquel hospital, por "su preparación en Bacteriología e Inmunología, por sus conocimientos de la patología y clínica de las enfermedades infecciosas, por su dedicación entusiasta a la especialidad y realización de numerosos trabajos de investigación y dirección de tesis para optar al título de médico”. Estos médicos fueron los doctores Abraham Horwitz, Roque Kraljevic y José Perroni.

La construcción del establecimiento tuvo varias interferencias hasta que finalmente en agosto de 1950 , comenzó su habilitación y funcionamiento $^{2,5}$.

Es en este momento cuando se destacó nítidamente la acción del Profesor Kraljevic. Nombrado Jefe de Servicio, organizó la atención especializada del paciente febril, en todos sus aspectos, cumpliendo a cabalidad los objetivos del Pabellón de Enfermedades Infecciosas: médicoasistencial, docente, experimental o de investigación y normativo en lo técnico, incorporando la técnica aséptica de atención al enfermo febril, permitiendo precisar diagnóstico y tratamiento de las enfermedades infecciosas en el país, etc.

Se centralizó la docencia de las enfermedades infecciosas tanto a nivel universitario de pre y post grado, de enfermería, etc, bajo la eficaz e inspirada dirección del Profesor Kraljevic, desfilando por allí los alumnos de la Facultad de Medicina de la Universidad de Chile, Universidad Católica, del Curso de Especialistas en Salud Pública y de las Escuelas de Enfermería, siendo secundado por un equipo médico que trataba de vibrar y de llevar a la práctica las normas y líneas directrices del Profesor Kraljevic.

Al cabo de 12 años de intensa y fructífera labor, las actividades se habían más que duplicado, llegando el Pabellón a constituirse en un Centro de Referencia Nacional de la Patología Infecciosa. Todo esto junto con los problemas presupuestarios del Hospital Ramón Barros Luco, 
que no permitían el desarrollo y la mantención adecuada del edificio, llevaron al doctor Kraljevic a tomar la decisión de "luchar con los mejores argumentos para obtener la separación e independencia del Pabellón en relación a la administración del Hospital Barros Luco, transformándose en un establecimiento con dirección y presupuesto independientes".

Finalmente, el $1^{\circ}$ de enero de 1963 , por acuerdo de la Dirección General y del Consejo del Servicio Nacional de Salud, pasó a obtener la categoría de Establecimiento, con el nombre de Hospital de Enfermedades Infecciosas Profesor Doctor Lucio Córdova, designación solicitada por el Profesor Kraljevic en memoria de su maestro.

El Profesor Kraljevic continuó su brillante labor como Director del Hospital hasta su jubilación en octubre de $1969^{2,5,6}$.

Ya que largo sería detallar su gran producción científica, no puedo dejar de mencionar su magnífica monografía sobre "El tifus murino y otras Rickettsiasis", que le sirvió de tesis para optar al título de Profesor Extraordinario de Enfermedades Infecciosas de la Universidad de Chile, en 1957, siendo el resultado de la búsqueda del tifus exantemático murino, mediante técnica de aislamiento de la Rickettsia typhi (antes llamada mooserii) en animales de laboratorio y la reacción de fijación del complemento. Constituyó el estudio sistemático de los caracteres clínicos y de laboratorio del tifus murino, realizado por primera vez en Chile ${ }^{2,6,7}$.

La otra obra, tanto y seguramente de gran valor sentimental y docente, es "Recuerdos de un viejo infectólogo. Contribución a la Historia de la Infectología en Chile (1937-1970)", finamente y muy bien comentada por el Profesor Doctor Mario Salcedo Sepúlveda, su digno sucesor en la docencia, quien comienza por decir que "es bueno que las memorias se escriban antes del olvido y estos recuerdos del doctor Kraljevic lo son no sólo de su propia vida personal y profesional, sino que también tocan los acontecimientos de muchas otras personas, entre éstas, las de quien les habla y evocan importantes sucesos de las ciencias médicas, de la medicina chilena y de sus instituciones"8.

Es verdad: este libro no sólo es la biografía de un gran maestro de las enfermedades infecciosas, sino que nos compromete e integra a todos los que tuvimos el privilegio de ser sus alumnos y luego sus ayudantes.

De las muchas actividades que el Profesor Kraljevic realizó en su vida profesional, es necesario destacar el haber sido el fundador y durante 20 años el Director del Departamento Médico de
Laboratorios Pfizer de Chile y a la vez, Jefe de Investigaciones Clínicas que se efectuaron en distintos hospitales chilenos, con los nuevos antimicrobianos y fármacos originados en los laboratorios Pfizer de USA ${ }^{5,12}$.

Es motivo de reconocimiento, que aún cuando se acogió a jubilación, en 1969, siguió prestando atención médica a los alumnos de la Universidad de Chile en el "Servicio Médico y Dental" de dicha Universidad. Esta tarea la realizó hasta cumplir 90 años de edad en el año 2001 ${ }^{3}$.

Después de ser en varias oportunidades, miembro del Directorio de la Sociedad Médica de Santiago, fue designado Presidente de dicha Sociedad, desde julio de 1959 hasta igual mes de 1961. En 1969 se le nombró Socio Honorario9.

En 1974 se le distinguió como Miembro Honorario del Servicio Nacional de Salud.

La Facultad de Medicina de la Pontificia Universidad Católica de Chile lo nombró Profesor Titular de Medicina y en 1984, la Facultad de Medicina de la Universidad de Chile, lo recibió como Profesor Emérito, anteriormente Profesor Titular de Enfermedades Infecciosas (1961). Un año después la Pontificia Universidad Católica de Chile le concedió Grado Honorífico Académico y lo nombró Miembro Académico de su Facultad de Medicina.

Junto con el recordado Profesor Antonio del Solar, el Profesor Kraljevic fue nombrado Miembro Honorario de la Sociedad Chilena de Infectología (Viña del Mar, 1993), la Junta Directiva, encabezada por el doctor Eduardo Gotuzzo, le confirió el título de Maestro de la Infectología Latinoamericana ${ }^{3}$.

También la Sociedad Médica de Santiago, en 1984, lo distinguió como Maestro de la Medicina Interna de Chile. "Hay en esta denominación societaria, el reconocimiento al maestro, el formador, al abridor de caminos, para la mejor realización del hombre, de la comunidad y de la disciplina que ha sido su quehacer"10. Todas estas características constituyen el bagaje del Profesor Kraljevic, en su quehacer universitario y profesional.

En 1988, le fue otorgado el título de Miembro Honorario de la Academia Chilena de Medicina (Instituto de Chile).

En agosto del año 2000, el Hospital de Enfermedades Infecciosas, celebró su quincuagésimo aniversario y en un acto efectuado en el Auditorio principal del establecimiento, que lleva el nombre del doctor Roque Kraljevic, se le otorgó un Diploma como Iniciador y Primer Director del Hospital. En un hermoso discurso en que agradeció la distinción, recordó con gran cariño, a todos 
los que fueron sus colaboradores, resaltando la importancia que ha tenido dicho nosocomio para el desarrollo de la especialidad en Chile ${ }^{11}$.

Nuestra Sociedad Chilena de Infectología volvió a galardonarlo en 1997, como Gran Maestro de la Infectología Chilena.

Por supuesto que este recuento aquí relatado no refleja ni con mucho, lo que es el Profesor Roque Kraljevic: creador, impulsor y transformador de todo lo que significa la patología infecciosa en nuestro país.

Con razón el 22 de diciembre de 1998 recibió en el Teatro Municipal de Santiago el Premio Sociedades Médicas de Chile a la Excelencia en Medicina, instituido por los Laboratorios Silesia, con ocasión del cincuentenario de dichos laboratorios.

Fue un honor y privilegio para el que escribe estas líneas referirse a la persona que ha sido su profesor y maestro durante largos años. Al finalizar mis palabras relaté lo que pudo ser producto de mi imaginación: "después de despedirse el Profesor Kraljevic del personal al dejar la Dirección del Hospital en 1969 con profundas y sinceras palabras en el Auditorio donde tantas veces predicó las buenas nuevas", lo acompañamos a su oficina. Ahí, mientras nerviosamente limpiaba sus anteojos, miraba por la ventana hacia donde años atrás estuvo el antiguo Servicio de Medicina y Enfermedades Infecciosas del Hospital Ramón Barros Luco. Quizás en ese momento la distancia que lo separaba le traía a la mente la imagen de tantos compañeros de ruta y el recuerdo de años de lucha y de trabajo recompensados al menos en parte, por el afecto y adhesión de los que fuimos sus alumnos y ayudantes ${ }^{13}$.

\section{Bibliografía}

1.- Zunino M E. Homenaje al doctor Roque Kraljevic. Bol Soc Chil Infect (1998); 4: 2.

2.- Laval R E. Homenaje al Profesor Roque Kraljevic. Sociedad de Neurología, Psiquiatría y Neurocirugía. 1973. Santiago de Chile (inédito)

3.- Profesor Dr. Roque Kraljevic Orlandini. Maestro de la Medicina Chilena. (inédito)

4.- Roque Kraljevic, el sembrador. Entrevista. Rev Chil Salud Pública (2002); 6: 37-9.

5.- Roque Kraljevic O. Recuerdos de un "viejo infectólogo". Contribución a la Historia de la Infectología en Chile. (1937-1970). Pfizer. Santiago - Chile. 1998.

6.- Laval R E. Reseña histórica de la atención de los pacientes con enfermedades infecciosas en Santiago de Chile, hasta la creación del Hospital Dr. Lucio Córdova. Rev Chil Infectol (2001); 18: 156-64.

7.- Kraljevic R. El tifus murino y otras Rickettsiasis. p. 9. Impta. Stanley. Stgo. de Chile. 1957.

8.- Salcedo S M. Libro de libros. Recuerdos de un "viejo infectólogo". Contribución a la Historia de la Infectología en Chile. (1937-1970). Rev Chil Infectol (1998); 15: 01-2.

9.- Larraín A C. La Sociedad Médica de Santiago y el Desarrollo Histórico de la Medicina en Chile. P. 435. Impta. Salesianos. Santiago - Chile.

10.- Rosselot J E. Maestros de la Medicina Interna Chilena. Rev Med Chile (2003); 131: 935-8.

11.- Kraljevic R. Discurso $50^{\circ}$ Aniversario Hospital de Enfermedades Infecciosas Prof. Dr. Lucio Córdova. 2000 (inédito)

12.- Acuña L G. Evolución de la terapia antimicrobiana: lo que era, lo que es y lo que será. Rev Chil Infectol (2003); 20 (Supl.): S7-S10

13.- Laval E R. Discurso de presentación del prof. Roque Kraljevic. Entrega de Premio Sociedades Médicas de Chile a la Excelencia en Medicina. 22 de diciembre de 1998. (inédito) 